\title{
Estimation of prevalence and risk factors for clostridium difficile infection: a neglected pathogen in a tertiary care setting in India
}

\author{
Lall $S^{1}$, Nataraj $G^{2}$, Mehta $\mathbf{P}^{3}$ \\ Dr. Sujata Lall, ${ }^{2}$ Dr. Gita Nataraj, Professor, ${ }^{3}$ Dr. Preeti Mehta, Senior Professor and Head, all authors are affiliated with \\ Department of Microbiology, Seth G.S.M.C and KEMH, Mumbai, India.
}

Address for Correspondence: Dr. Sujata Lall, Email: sujatamed@gmail.com

\begin{abstract}
Introduction: Clostridium difficile is a Gram positive spore bearing anaerobic bacillus increasingly associated with both community and hospital acquired colitis and diarrhoea. Among all the risk factors, inclusive of the host and the environmental factors, antibiotics are the most important ones, as validated by various studies. Patients receiving antibiotics and other drugs such as immunosuppressives, chemotherapeutics and proton pump inhibitors may also be important risk factors. The present study was planned to find out the prevalence and risk factors for Clostridium difficile associated diarrhoea (CDAD). Material and Methods: After taking approval from ethics committee ,150 patients with antibiotic associated diarrhoea were taken as study group and 50 patients with exposure to antibiotics but who did not develop diarrhoea were taken as controls. Stool specimens were processed for both culture on Cycloserine Cefoxitin Fructose Agar (CCFA) and toxin detection by IVD Tox A+B ELISA. Risk factor analysis was done by calculating odds ratio and significance of $\mathrm{p}$ value among various parameters related to drugs and other factors. Result: Prevalence of CDAD in the present study was $8.67 \%$. Third generation cephalosporins, clindamycin, aminoglycosides, quinolones and trimethoprim sulfamethoxazole were significant risk factors for both antibiotic associated diarrhoea (AAD) and Clostridium difficile associated diarrhoea (CDAD).Use of proton pump inhibitors, immunosuppressants and prolonged stay in the hospital were other significant risk factors associated with CDAD. Conclusion: Although CDAD occurs at a lower frequency in this setting, rational antibiotic policy and infection control measures should be followed to prevent its occurrence and nosocomial spread.
\end{abstract}

Keywords- Antibiotics, Diarrhoea, Clostridium difficile

\section{Introduction}

Clostridium difficile is a Gram positive spore bearing anaerobic bacillus increasingly associated with both community and hospital acquired colitis and diarrhea. It is the most common identifiable bacterial cause of nosocomial diarrhoea associated with antibiotic use and one of the most common anaerobic infections [1]. CDAD (Clostridium difficile associated diarrhoea) is a life threatening disease with an attributable mortality of $6-15 \%$ and up to $25 \%$ in frail elderly people [2].

The clinical presentations in increasing order of severity include asymptomatic carriage, colitis without pseudo membrane formation, pseudomembranous colitis

Manuscript received: $10^{\text {th }}$ March 2017

Reviewed: $18^{\text {th }}$ March 2017

Author Corrected: $25^{\text {th }}$ March 2017

Accepted for Publication: $31^{\text {st }}$ March 2017
(PMC) and fulminant colitis [3, 4]. Among all the risk factors, inclusive of the host and the environmental factors, antibiotics are the most important ones, as validated by various studies.

Patients receiving antibiotics and other drugs such as immune-suppressives, chemotherapeutics and proton pump inhibitors may also be important risk factors [5].

Outbreaks in various parts of the world have been reported including the mutant hypervirulent strain, NAP1/BI/027 (North American Pulse-field gel electrophoresis type1 / restriction endonuclease analysis $\mathrm{BI} /$ ribotype 027) [6] has finally put the spotlight on this pathogen. 


\section{Materials and Methods}

Study design- Prospective case control study carried out after obtaining ethics committee permission

Setting- From January 2012 to December 2013 in a tertiary care hospital

\section{Inclusion Criteria}

1) Diarrhoea and history of antibiotic use either in the previous month or recently since 5 days.

2) Pseudomembranous colitis detected on lower gastrointestinal endoscopy referred for $C$.difficile detection and no other recognized aetiology of diarrhoea.

\section{Exclusion criteria}

1) Diarrhoea during the first 72 hours of admission in a hospital

2) Neonates and psychiatric patients

Study size- 150 cases and 50 controls of any age and gender.

Participants- Medicine, allied medicine and paediatric departments were informed to send stool samples from patients who satisfied inclusion criteria mentioned above after taking written, informed consent. Also the study investigator visited different wards to identify patients. Diarrhoea was defined as six watery stools over 36 hours or three unformed stools in 24 hours for 2 days or eight unformed stools over 48 hours. Controls were those patients admitted during the study period who had taken antimicrobials for at least 5 days but did not develop diarrhoea.

Variables- A detailed study Performa was filled up for each one of them, which included various parameters like age, sex, severity of diarrhoea with duration ward and unit of admission, ICU stay, association with other symptoms like abdominal pain, fever, antibiotics used and their duration, other significant laboratory investigations, duration of hospital stay ,presence of nasogastric feed and provisional diagnosis. Associated and/or underlying illnesses (inflammatory bowel disease, prior abdominal surgery, malignancy, prior hospitalization, immunosuppressive state), and addictions were recorded. Exposure to immunosuppressive agents, cancer chemotherapy, and Proton pump inhibitors (PPI) was noted.

\section{Methodology}

\section{Microbiological Method}

Specimen collection: Faecal samples were collected from antibiotic associated diarrhoea cases in sterile wide mouthed screw capped containers and immediately transferred to the laboratory. Specimens were immediately processed for microscopy, anaerobic culture and ELISA. For ELISA, unpreserved specimens were kept at $2-8^{\circ} \mathrm{C}$ and tested within 24 hours of collection. Specimens that could not be tested within this time were frozen at $-20^{\circ} \mathrm{C}$ or lower until used.

\section{MICROSCOPY:}

A direct wet mount for faecal leucocytes and a Gram's stain for detecting organisms with characteristic morphology as that of $C$. difficile which appears as a gram positive bacillus with subterminal spore were carried out. (Figure 1)

Culture- For C. difficile isolation, stool samples were inoculated into Robertson's cooked meat (RCM) broth for enrichment, and incubated at $37^{\circ} \mathrm{C}$ for $24-48$ hours. Samples were also directly plated on Cycloserine Cefoxitin Fructose agar (CCFA). RCM was subcultured after 48 hours on CCFA.

All the plates were incubated anaerobically in McIntosh Filde's jar for 48-72 hours. Anaerobiosis was monitored as per standard protocol by keeping a known strain of pseudomonas aeruginosa inoculated in a citrate slant in the jar. Validation of the method of isolation of $C$. difficile by culture was done by subculture of a known standard strain of C.difficile (ATCC 9689) on (CCFA), HiMedia and incubating anaerobically. 


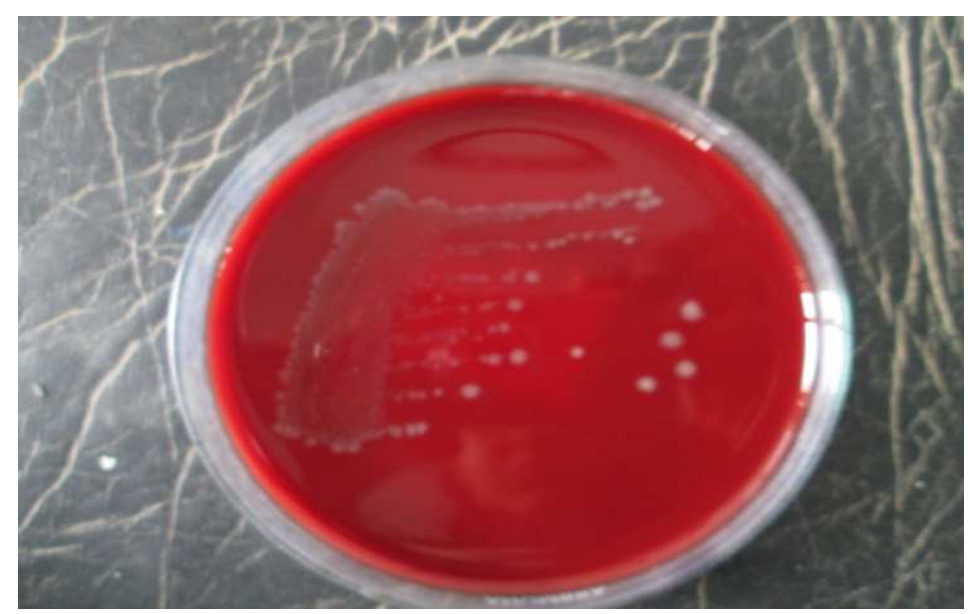

FIG-1: Culture of Clostridium difficile on CCFA

After 48 hours of incubation on CCFA, colonies of C .difficile were $4 \mathrm{~mm}$ or larger, flat to slightly raised rhizoid colonies which had a speckled opalescence and strong horse manure like odour (Figure 2). Colonies of distinctive morphology were Gram's stained and subcultured in Robertson's cooked meat medium. A test for aero tolerance was done to confirm that each colony type is an obligate anaerobe. Positive cultures were identified by gross colonial morphology, gram's stain characteristics and standard biochemical tests .glucose, fructose, and mannose were fermented, and lactose and sucrose were not fermented .Gelatin was liquefied and lecithinase was not produced.

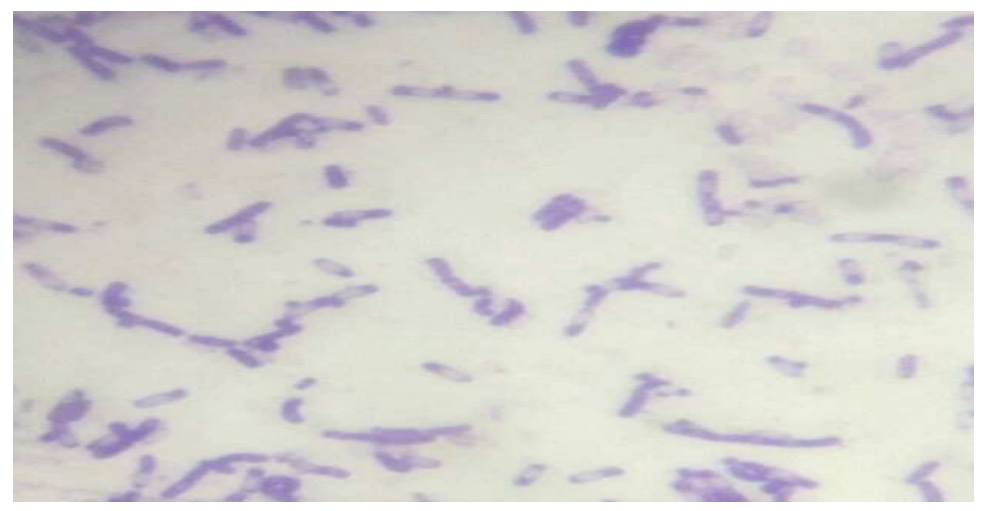

FIG-2: Morphology of Clostridium difficile in Gram's stain

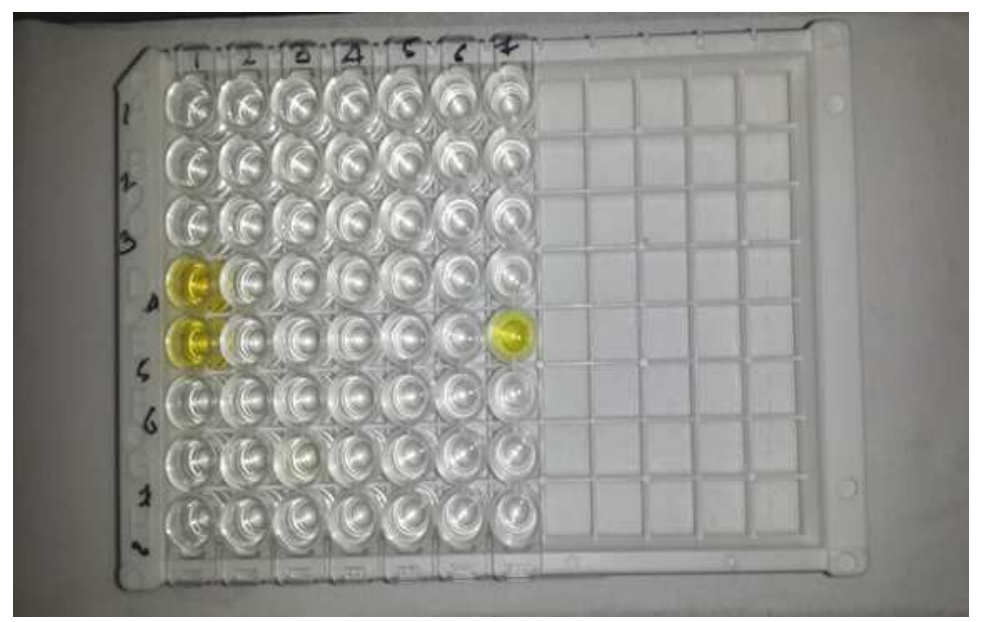

FIG-3: ELISA for TOX A+B detection of C.difficile 
Toxin Assay Elisa- For toxin assay $C$. difficile Toxin A+B Stool Antigen Microwell ELISA Kit manufactured by IVD Research Inc. Carlsbad, USA was used. (Figure3). The test was carried out as per manufacturer's instructions.

Any sample well that was obviously more yellow than the negative control well or gave an absorbance reading of 0.15 OD units and above indicated that the sample contained $C$. difficile toxin and vice versa.

Selecting Cases- The samples giving positive reaction in ELISA and which had grown C.difficile in culture were considered as cases. All the patients were followed up for their response to discontinuation of antibiotic therapy and/or treatment with metronidazole and treatment with vancomycin.

Statistical Analysis- A case control study was carried out. The study subjects were divided into two groups, group A were those with AAD in whose stool specimen C. difficile was detected and Group B were those with AAD in whose stool specimens C. difficile was not detected. Data was analysed by frequency percentage. Odds ratio was calculated for risk factors which were taken as parameters in a case record form during specimen collection from patients. To determine the significance of the value obtained, Chi-square test and fisher exact test was used, $\mathrm{p}$ value $</=0.05$ was considered significant.

\section{Result}

The total sample size of the study was 150 patients who were having antibiotic associated diarrhoea. Of these, 31 were children and 119 were adults.50 age and gender (for adult group) matched controls were also taken from the same hospital setting.

Out of 150 patients in the study group, Clostridium difficile was isolated from the stool of 4 patients (3adults and one child). 13 faecal samples tested positive for Toxin A+B by Enzyme Immunoassay (11 adults and 2 children). All the 4 samples tested positive by culture were found to be toxigenic by ELISA.

No faecal sample from the control group was positive for C.difficile by culture or ELISA. The main organ system involvement for which the patient got admitted was noted with the help of analysis of diagnosis and clinical history as shown in table 1

Table-1-Primary system involvement for antibiotic therapy.

\begin{tabular}{|c|c|c|}
\hline System Involved & $\begin{array}{c}\text { Group B( n=137) } \\
\text { No of patients (\%) }\end{array}$ & $\begin{array}{c}\text { Group A } \\
(\mathbf{n = 1 3}) \\
\text { No of Patients (\%) }\end{array}$ \\
\hline Gastrointestinal & $38(27.7 \%)$ & $3(23 \%)$ \\
\hline Respiratory & $26(19 \%)$ & $1(7.7 \%)$ \\
\hline Genitourinary & $14(10.2 \%)$ & 0 \\
\hline Haematological & $10(7.29 \%)$ & $2(15.38 \%)$ \\
\hline Central nervous & $22(16 \%)$ & $2(15.38 \%)$ \\
\hline System & $20(14.6 \%)$ & $1(7.7 \%)$ \\
\hline Others & $3(2.18 \%)$ & $1(7.7 \%)$ \\
\hline Poisoning & $1(0.72 \%)$ & $2(1.7 \%)$ \\
\hline Post organ Transplant & $3(2.18 \%)$ & \\
\hline Tuberculosis & & \\
\hline
\end{tabular}

The age and gender distribution amongst group A and B was also done as shown in table 2

Maximum cases were from 31-45 years age group, males[9]were more than females[4].In patients who had AAD not attributed to C.difficile, maximum patients were from $>45$ years age group. 
Table-2: Age and gender distribution in the study group and controls

\begin{tabular}{|c|c|c|c|}
\hline \multirow{2}{*}{ Age in years } & $\begin{array}{c}\text { (Group A) } \\
\text { Cases } \\
\mathbf{n = 1 3}\end{array}$ & $\begin{array}{c}\text { (Group B) } \\
\text { AAD without } \text { C. difficile } \\
\mathbf{n = 1 3 7}\end{array}$ & $\begin{array}{c}\text { Control group } \\
\mathbf{n}=\mathbf{5 0}\end{array}$ \\
\hline $0-15$ & 2 & 29 & 11 \\
M & 1 & 18 & 6 \\
F & 1 & 11 & 5 \\
\hline $16-30$ & 1 & 31 & 10 \\
M & 1 & 25 & 6 \\
F & 0 & 6 & 4 \\
\hline $31-45$ & 6 & 32 & 10 \\
M & 4 & 22 & 3 \\
F & 2 & 10 & 19 \\
\hline$>45$ & 4 & 32 & 3 \\
\hline M & 3 & 13 & 16 \\
\hline F & 1 & & 3 \\
\hline
\end{tabular}

The antibiotics taken in both study and control group patients were noted and odds ratio was found to see their significance in association with antibiotic associated diarrhoea. As shown in table 3

Table-3: Risk factors for antibiotic associated diarrhoea.

\begin{tabular}{|c|c|c|c|c|}
\hline Class of antibiotics & Study group(n=150) & $\begin{array}{c}\text { Control } \\
\text { group(n=50) }\end{array}$ & Odds ratio & p value \\
\hline $\begin{array}{c}\text { Cephalosporins } \\
\text { First generation } \\
\text { Second generation } \\
\text { Third generation }\end{array}$ & 40 & 8 & $\mathbf{1 . 9 0 9 1}$ & 0.1305 \\
$\begin{array}{c}\text { Intravenous } \beta \text { lactam/ } \beta \text { lactamase } \\
\text { inhibitor }\end{array}$ & 80 & 4 & $\mathbf{3 . 5}$ & 0.0242 \\
\hline Amoxicillin-Clavulanic acid & 48 & 17 & $\mathbf{2 . 2 1 8 5}$ & $\mathbf{0 . 0 1 9}$ \\
\hline Macrolides & 62 & 16 & 0.9135 & 0.7938 \\
\hline Lincosamide & 58 & 17 & 1.22 & 0.55 \\
\hline Carbapenems & 45 & 8 & 2.25 & 0.05 \\
\hline Narrow spectrum penicillins & 56 & 14 & $\mathbf{1 . 5 3}$ & 0.23 \\
\hline Aminoglycosides & 45 & 10 & 1.71 & 0.17 \\
\hline Trimethoprim-Sulfamethoxazole & 76 & 16 & $\mathbf{2 . 1 8}$ & $\mathbf{0 . 0 2}$ \\
\hline
\end{tabular}

The antibiotics used regularly in hospitals were evaluated for both group A and Group B and odds ratio was calculated to find out the significance for clostridium difficile associated diarrhoea as shown in table 4. 
Table-4: Antibiotics as risk factors for Clostridium difficile associated diarrhea.

\begin{tabular}{|c|c|c|c|c|}
\hline Class of antibiotics & $\begin{array}{c}\text { Group A } \\
\text { Cases(n=13) }\end{array}$ & $\begin{array}{c}\text { Group B } \\
(\mathbf{n = 1 3 7})\end{array}$ & Odds ratio & p value \\
\hline $\begin{array}{c}\text { CEPHALOSPORINS } \\
\text { First generation }\end{array}$ & 2 & 38 & 0.47 & 0.34 \\
Second generation & 2 & 33 & $\mathbf{5 . 1 1}$ & $\mathbf{0 . 0 3}$ \\
\hline Third generation & 11 & 71 & $\mathbf{1 . 3 6}$ & 0.60 \\
\hline $\begin{array}{c}\text { Intravenous } \beta \text { lactam/ } \\
\beta \text { lactamase inhibitors }\end{array}$ & 5 & 43 & $\mathbf{2 . 4}$ & 0.13 \\
\hline Amoxicillin-Clavulanic acid & 8 & 54 & $\mathbf{5 . 5}$ & $\mathbf{0 . 0 2}$ \\
\hline Quinolones & 11 & 68 & $\mathbf{1 . 6}$ & 0.38 \\
\hline Macrolides & 5 & 37 & $\mathbf{3 . 0 6}$ & $\mathbf{0 . 0 5}$ \\
\hline Clindamycin & 8 & 57 & $\mathbf{3 . 1 5}$ & 0.06 \\
\hline Aminoglycosides & 9 & 51 & 1.04 & 0.94 \\
\hline Narrow spectrum Penicillins & 4 & 58 & 0.41 \\
\hline Aminoglycosides & 8 & 51 & 0.24 \\
\hline
\end{tabular}

The patients were administered many other drugs besides antibiotics in the hospital. Odds ratio between group A and B for these drugs was calculated as shown in table 6.

Table 5: Risk factors other than drugs for Clostridium difficile associated diarrhea.

\begin{tabular}{|c|c|c|c|c|}
\hline Risk factor & $\begin{array}{c}\text { Group A } \\
(\mathbf{n = 1 3})\end{array}$ & $\begin{array}{c}\text { Group B } \\
(\mathbf{n = 1 3 7})\end{array}$ & $\begin{array}{c}\text { ODDS } \\
\text { RATIO }\end{array}$ & $\mathbf{2 . 7 7}$ \\
\hline Duration of stay in hospital>5 days & 12 & 133 & $\mathbf{4 . 3}$ & $\mathbf{0 . 0 1}$ \\
\hline Intensive care unit stay & 9 & 47 & $\mathbf{3}$ & 0.07 \\
\hline Surgery & 5 & 28 & $\mathbf{1 . 2}$ & $\mathbf{0 . 0 4}$ \\
\hline Tube feeding & 6 & 55 & 0.66 & 0.5 \\
\hline Smoking & 4 & 37 & 0.49 & 0.37 \\
\hline Alcohol & 2 & 36 & $\mathbf{1 . 2}$ & 0.7 \\
\hline Hematochaezia & 4 & 8 & $\mathbf{1 . 3}$ & 0.76 \\
\hline Inflammatory bowel disease & 4 & 1 & 60 & $\mathbf{0 . 0 0 0 5}$ \\
\hline Malignancy & 4 & 0 & Very high & $\mathbf{0 . 0 0 0 2}$ \\
\hline Organ transplant & 3 & 6 & $\mathbf{9 . 7}$ & $\mathbf{0 . 0 0 2}$ \\
\hline Chemotherapy & 4 & 15 & $\mathbf{3 . 4}$ & $\mathbf{0 . 0 1}$ \\
\hline
\end{tabular}

Various other factors besides antibiotic and drugs were evaluated which were important during the stay in hospital. The odds of occurrence of CDAD in group A was higher in the presence of intensive care unit stay, past surgery, tube feeding, inflammatory bowel disease, chemotherapy, prior hospital stay, organ transplant, hematochaezia and it was statistically significant in case of intensive care unit stay, malignancy, organ transplant, chemotherapy, prior hospital stay and duration of stay in hospital for more than 5 days. 
Of 13 positive cases of C.difficile, 2 patients died. Mortality was attributed to chronic renal failure in one patient and septicaemia in another (fungal sepsis in a case of Promyelocytic leukaemia). Seven patients responded on stopping the inciting antibiotic, two patients responded successfully on treatment with metronidazole and two more patients required additional vancomycin therapy.

Table-6: Drugs used in hospital other than antibiotics as risk factors for Clostridium difficile associated diarrhea.

\begin{tabular}{|c|c|c|c|c|}
\hline Other drugs received while in hospital & Group $\mathbf{A}(\mathbf{n}=\mathbf{1 3})$ & $\begin{array}{c}\text { Group } \\
\mathbf{B}(\mathbf{n}=\mathbf{1 3 7})\end{array}$ & $\begin{array}{c}\boldsymbol{p} \text { - } \\
\text { ODALUE }\end{array}$ \\
\hline Proton pump inhibitors & 12 & 95 & $\mathbf{3 . 8}$ & $\mathbf{0 . 0 0 4}$ \\
\hline H-2 Blocker & 5 & 46 & $\mathbf{1 . 4}$ & 0.57 \\
\hline laxatives & 2 & 32 & 0.59 & 0.51 \\
\hline Non -steroidal anti-inflammatory drugs & 8 & 71 & $\mathbf{1 . 4 8}$ & 0.50 \\
\hline Corticosteroids & 7 & 35 & $\mathbf{3 . 4}$ & $\mathbf{0 . 0 3}$ \\
\hline Immunosuppressant & 10 & 46 & $\mathbf{6 . 6}$ & $\mathbf{0 . 0 0 5}$ \\
\hline
\end{tabular}

\section{Discussion}

The present study on 150 patients with antibiotic associated diarrhoea and 50 controls was carried out to determine the prevalence of Clostridium difficile associated diarrhoea using culture and toxin assay. In the present study, $8.67 \%$ of suspected AAD cases were either culture positive or toxin assay positive for Clostridium difficile. All specimens culture positive were also positive for the toxin assay. Culture did not detect any additional positive case. The culture positivity rate was $3.34 \%$. Low culture positivity rates have been documented in other studies as given in Table 7.The higher rates

Table-7: Culture and Elisa positivity rates of $C$.difficile in various studies.

\begin{tabular}{|c|c|c|c|c|c|}
\hline Journal & Author & Year/place & $\begin{array}{c}\text { No of } \\
\text { patients }\end{array}$ & $\begin{array}{l}\text { Culture positivity / } \\
\text { Culture media used }\end{array}$ & $\begin{array}{c}\text { ELISA } \\
\text { Positivity / Kit used }\end{array}$ \\
\hline JDD & 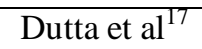 & 1993/Calcutta & 111 & $3.6 \% / \mathrm{CCFA}$ & Not done \\
\hline J Hosp Inf & $\begin{array}{c}\text { Dhawan et } \\
\mathrm{al}^{11}\end{array}$ & 1999/New Delhi & 66 & $3.8 \% / \mathrm{CCFA}$ & $\begin{array}{c}5.7 \% \text { (premier toxins A } \\
\text { and B, Meridian) } \\
\text { Bioscience, Ohio, USA) }\end{array}$ \\
\hline IJMR & Gogate et al $^{16}$ & 2004/Mumbai & 250 & $7.2 \% / \mathrm{CCFA}$ & $\begin{array}{c}\text { 14\% (Ridascreen } \\
\text { C.difficile Toxin A/B ,R- } \\
\text { Biopharm, Germany) }\end{array}$ \\
\hline CID & Gravel et al ${ }^{19}$ & 2009/Canada & 1430 & Not done & $46 \%$ \\
\hline IJG & $\begin{array}{l}\text { Meghraj et } \\
a l^{13}\end{array}$ & 2011/Mumbai & 99 & Not done & $17 \%$ \\
\hline JAPI & $\begin{array}{c}\text { Kaneria et } \\
\mathrm{al}^{18}\end{array}$ & 2012/Mumbai/ & 50 & Not done & $10 \%$ \\
\hline JAPI & $\begin{array}{l}\text { Shashidhar } \\
\text { eat al }\end{array}$ & 2013/Manipal & 25 & $8 \%$ (CCFA) & $\begin{array}{c}\text { 16\% (premier toxins A } \\
\text { and B, Meridian } \\
\text { Bioscience, Ohio, USA) }\end{array}$ \\
\hline Infections & $\begin{array}{c}\text { Heimesaat et } \\
\mathrm{al}^{20}\end{array}$ & 2005/Germany & 693 & Not done & $11.4 \%$ \\
\hline Anaerobe & 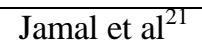 & 2010/Kuwait & 697 & N0t done & $8 \%$ \\
\hline
\end{tabular}


in some of the studies maybe attributed to a low sample size [15] or due to bias of results with study done on children of age group 5-12 years as subjects. [16] Children are reported to have higher colonization rates of C. difficile [1]. Lower culture positivity rates can be due to delay in sample transportation to the laboratory, inefficient management of anaerobiosis due to repeated subculture of the isolate which leads to loss of viability, C.difficile being overgrown by many other microorganisms on CCFA, sampling error inherent to uneven distribution of $C$. difficile in the faecal samples or dilutional effects of diarrhoea as culture is dependent upon the presence of spores or viable vegetative cells [22] Culturing of non-diarrheal stools also leads to false negative results. [23]

Prevalence of CDAD is around 2-4\% in patients without diarrhoea and 7-30\% in patients with diarrhoea in different hospital based studies [151617,27]. In the present study, the prevalence of C.difficile was $8.67 \%$ in hospitalized diarrhoea patients and $0 \%$ in non-diarrhoea controls. Gupta et al [29] have reported C.difficile isolation rate of $25.3 \%$ in hospitalized patients with diarrhoea and $4.3 \%$ in controls admitted for other ailments. Niyogi et al [10] have reported $4 \%$ in hospitalized patients with diarrhoea and $2.7 \%$ in non-diarrhoea controls. Bhattacharya et al [27] isolated C. difficile as a sole pathogen from $7.3 \%$ of 233 patients with acute diarrhoea. Vaishnavi et al [28] reported $30 \%$ positivity for $C$. difficile toxin in hospitalized patients of all age groups receiving single to multiple antibiotics for various diseases, but only in $7 \%$ of patients not receiving antibiotics. Some recent studies estimated a prevalence rate of $10 \%$ [18], 14\% [16] and $17 \%$ [13]. The isolation of C.difficile in non-diarrhoea controls in other studies maybe related to colonization. Colonization by $\mathrm{C}$. difficile in asymptomatic adults depends upon presence of long standing disease, contact with suspected patient of CDAD, and length of hospital stay which increases the chances of contact with spores [1]. Low carriage rates in asymptomatic adults in the present study may be due to very low numbers of CDAD patients thereby minimizing exposure risk, inclusion of non-diarrheal controls and incorporation of all age groups rather than only paediatric population which show high carriage rate.

In the present study, prolonged stay in the hospital for more than 5 days was a significant risk factor (0.0004) similar to the findings of Kaneria et al. Other studies in literature have also shown that prolonged ICU stay is an important host related risk factor [18, 26, 27,28]. Meghraj et al in a study done in Mumbai found that ICU stay, is associated with $C$. difficile toxin positivity on univariate analysis[13].In the present study, maximum cases of AAD were from Medical ICU[6] followed by Intensive Respiratory Care Unit[4].

Dhawan et al from Delhi reported that the highest number of $C$. difficile toxin positive cases were from stool samples of patients hospitalized in the hematology/oncology ward [25 samples, 67.5\% of all positive cases), followed by gastrointestinal surgery, neurology and nephrology wards [11]. In the present study, patients admitted to hematology unit formed the second largest group of cases.

In a recent study done in south India, most of the patients with AAD were from general medical wards, followed by oncology, surgery and paediatric wards. Prolonged duration of antibiotics was partly responsible for the increasing incidence along with severe underlying illness [15]. In the present study, the higher number of cases from MICU could be because of prolonged stay of patients and treatment with multiple antibiotics for a longer duration of time.

$\mathrm{CDAD}$ has been reported to be more common in women and older patients [29]. Studies from India have reported varying male female ratios. In the present study, amongst 13 positive cases, 9 were males $(60.9 \%)$ and 4 were females. Maximum numbers of positive cases were found in the age group of 30-45 years followed by those more than 45 years of age. Similar male preponderance and higher age association has been reported in other studies from India [12, 15, 18].

The increased risk of acquiring $C$. difficile infection in the elderly may be due to age-related changes in fecal flora, immune senescence i.e. impaired ability of neutrophils to phagocytose and kill C.difficile and decrease in the capacity of serum to neutralize toxins with increasing age, or the presence of other underlying diseases. Antibiotics and other drugs such as immunosuppressive agents, proton pump inhibitors and cancer therapeutics are significant risk factors for CDAD precipitation but the predominant risk factor associated with acquisition of $C$. difficile is antibiotic use in the preceding 2 months, with even a single dose capable of doing the harm. Risk is greater when the patients are on multiple antibiotics and undergo longer course of therapy [1]. 
In the present study the more strongly associated antimicrobials with CDAD were quinolones, third generation cephalosporins, macrolides, and amoxicillin-clavulanic acid.

Since many patients in the present study had concurrently received multiple antimicrobials, the risk associated with the individual drugs could have been confounded by other drugs. Kaneria et al [18] reported cephalosporins as the most important cause of $\mathrm{AAD}$ in their study while Vishwanath et al [15] reported treatment with clindamycin or fluoroquinolones along with third generation cephalosporin to be more predisposing.

Recent history of fluoroquinolone administration is an important risk factor for CDAD [13]. In a study comparing prevalence of CDAD in those receiving antibiotics and those not receiving antibiotics Vaishnavi et al,[30] report 30\% positivity for $C$. diffcile toxin in the former group, but only seven per cent in the latter group.

C. difficile colonization is more frequent in units where broad spectrum antibiotics and immunosuppressants are widely spread [1]. In the present study, $76.9 \%$ of the CDAD cases had received immunosuppressants during their course in hospital, $53.8 \%$ of the cases had received corticosteroids and three cases of CDAD had received organ transplant. Receiving immunosuppressants was significantly associated as a risk factor ( $\mathrm{p}$ value $<0.0001$ ).

In a study done by Meghraj et al, corticosteroids were associated with all of the positive cases of CDAD ${ }^{13}$. West $e t$ al [31] while investigating the effects of corticosteroids and cyclosporine on CDAD acquisition in immune-suppressed transplant recipients observed that there was an increased incidence of $C$. difficile colitis in paediatric kidney-pancreas recipients. They reported overall eight per cent incidence of CDAD with $16 \%$ in the paediatric kidney group and $15.5 \%$ in the kidney-pancreas group.

Dallal et al. [32] reported 31\% incidence of CDAD in lung transplant patients compared to1.6\% overall. Wong et al, [33] also reported that $C$. difficile and medication were the commonest colorectal cause of morbidity after orthotopic liver transplantation in addition to ulcerative colitis and cytomegalovirus infection.

Administration of tacrolimus, an immunosuppressive agent indicated for prophylaxis of organ rejection after allogeneic kidney or liver transplant, resulted in the development of CDAD. Emoto etal,[34] reported severe CDAD in $6.1 \%$ of patients receiving Cisplatin based combination chemotherapy for ovarian malignancies. Kumar etal, [35] reported that 19 out of 58 patients .treated with Methotrexate or Mesalamine for psoriasis were positive for $C$. difficile toxins. In the present study, malignancy was a significant risk factor ( $\mathrm{p}$ value 0.0117) along with chemotherapy administration $(\mathrm{p}<0.0088)$ for CDAD positive cases.

In the present study proton pump inhibitors were significantly associated as a risk factor (p value <0.0048)

Proton pump inhibitors (PPI) inhibit the gastric acid secretion by interfering with the activity of $\mathrm{H}+/ \mathrm{K}+-\mathrm{ATP}$ ase of the parietal cells and may thus contribute to the pathogenesis of CDAD by altering the intestinal flora. Patients are about twice as likely to develop CDAD with PPI, due to increased survival of spores by elevated gastric $\mathrm{pH}$ levels [26, 51,52].

In the present study, $46 \%$ of the CDAD positive cases were tube fed either after an operative procedure or after prolonged ambulation. Bliss et al,[36] studied the incidence of C.difficile acquisition and CDAD in tube-fed and non-tube fed patients and reported that tube-fed patients, especially those receiving post pyloric tube feeding are at greater risk for development of CDAD than are hospitalized, non-tube-fed patients.

Fulminant colitis with increased mortality is reported more frequently during outbreaks of $C$. difficile infection in patients with inflammatory bowel disease [37] but in the present was not associated with CDAD. Balamurugan et al found increased faecal carriage of $C$. difficile in patients with ulcerative colitis as compared to healthy individuals [38].

Liquid stool with mucus and blood was also a sensitive predictor for AAD in the present study. Presence of spores in Gram's stain, faecal leucocytes more than 5 per high power field was also a definite predictor of $C$. difficile diarrhoea, though Feketly et al [39] reported on the contrary. 
Of the 13 patients with $\mathrm{CDAD}$, two expired. Of the remaining, 7 responded on stoppage of antibiotic therapy, 2 responded to treatment with metronidazole and 2 responded to treatment with vancomycin.

The cause of death being renal failure in one case and septicaemia in another. Discontinuation of antibiotic therapy withdraws the offending agents but is often not appropriate if the indication for such therapy was correct. Metronidazole is suggested as the first line drug for the treatment of $C$. difficile infection, and therefore the policy of the use of metronidazole in the treatment of suspected CDAD in a hospital should be recommended.

\section{Conclusion}

Though the prevalence rate in our study was not much, still this pathogen needs to be considered as a significant hospital associated infection, because it is difficult to eradicate spores from the hospital surroundings which persist for months and become ready to infect a new host. Active and aggressive surveillance, infection control education, training and regular audits of the practices prevalent in the hospital are required at this stage to contain the spread of this infection.

\section{Funding: Nil, Conflict of interest: None \\ Permission of IRB: Yes}

\section{References}

1Vaishnavi C. Established and potential risk factors for Clostridium difficile infection. Indian J Med Microbiol. 2009; 27(4):289-300.

2. Vaishnavi C. Clostridium difficile infection: clinical spectrum and approach to management. Indian $\mathbf{J}$ Gastroenterol. 2011; 30: 245-54

\section{Lyerly DM, Krivan HC, Wilkins TD. Clostridium} difficile: its disease and toxins. Clin Microbiol Rev. 1988 Jan; 1(1):1-18.

4. Vaishnavi C. Clinical spectrum and pathogenesis of clostridium difficile associated diseases. Indian J Med Res 2010; 131: 487-499

5. Jobe BA, Grasley A, Deveney KE, Sheppard BC. Clostridium difficile colitis: an increasing hospitalacquired illness. Am J Surg. 1995; 169: 480-483. doi: 10. 1016/S0002-9610(99)80199-8

6. Goorhuis A, Van der Kooi T, Vaessen N, Dekker FW, Van den Berg R, Harmanus C, van den Hof S, Notermans DW, Kuijper EJ. Spread and epidemiology of Clostridium difficile polymerase chain reaction ribotype 027/toxinotype III in The Netherlands. Clin infect dis 2007; 15; 45(6):695-703.

7. Delmée M, Van Broeck J, Simon A, Janssens M, Avesani V. Laboratory diagnosis of Clostridium difficile-associated diarrhoea: a plea for culture. J Med Micorbiol.2005 ;54(Pt 2):187-91.
8. Vaishnavi C. Diagnostic approach to Clostridium difficile infection. Indian J Gastroenterol. 2010;29: 137-139.

9.Ayyagari A, Sharma P, Venkateswarlu, Mehta S, Agarwal KC: Prevalence of Clostridium difficile in pseudomembranous and antibiotic-associated colitis in north India. J Diarrhoeal Dis Res 1986, 4(3):157160.

10 Niyogi SK, Bhattacharya SK, Dutta P, Naik TN, De SP, Sen D, Saha MR, Datta D, Nair GB, Mitra U, et al: Prevalence of Clostridium difficile in hospitalized patients with acute diarrhoea in Calcutta. J Diarrhoeal Dis Res 1991, 9(1):16-19.

11. Dhawan B, Chaudhry R, Sharma N: Incidence of Clostridium difficile infection: a prospective study in an Indian hospital. J Hosp Infect 1999, 43 (4): 275280 .

12. Chaudhry R, Joshy L, Kumar L, Dhawan B: Changing pattern of Clostridium difficile associated diarrhoea in a tertiary care hospital: a 5 year retrospective study. Indian J Med Res 2008, 127(4): 377-382.

13. Ingle M, Deshmukh A, Desai D, Abraham P, Joshi A, Rodrigues C, Mankeshwar R:Prevalence and clinical course of Clostridium difficile infection in a tertiarycare hospital: a retrospective analysis. Indian J Gastroenterol 2011, 30(2):89-93. 
14. Gerding DN, Johnson S, fiterson LR, Mulligan ME, Silva J J7:Clostridium diffcile-associated diarrhea and colitis. Infect Control Hosp Epidemiology 1995; 16: 459-477.

15. Shashidhar Vishwanath, Arpita Singhal, Annet D'Souza, Chiranjay Mukhopadhyay, Muralidhar Varma, Indira Bairy. Clostridium difficileInfection at a Tertiary Care .Hospital in South India. JAPI Nov 2013; $61: 30-32$

16. Gogate A, De A, Nanivadekar R, Mathur M, Sarawathi K, Jog A et al. Diagnostic role of stool culture and toxin detection in antibiotic associated diarrhea due to Clostridium difficile in children. Indian J Med Res 2005;122: 518-24

17. Dutta P, Niyogi SK, Mitra U, Rasaidy R, Bhattacharya MK, Chakraborty S, et al. Clostridium difficile in antibiotic associated pediatric diarrhoea. Indian Pediatr1994; 31:121-6.

18. Mala V Kaneria, Sonia Paul Incidence of Clostridium Difficile Associated Diarrhoea in a Tertiary Care Hospital .JAPI• November 2012; 60:26-28

19. Gravel et al, Health Care-Associated Clostridium difficile Infection in Adults Admitted to Acute Care Hospitals in Canada: A Canadian Nosocomial Infection Surveillance Program Study. Clinical Infectious Diseases2009; 48:568-76

20. Heimesaat MM, Granzow $\mathrm{K}$, Leidinger $\mathrm{H}$, Liesenfeld O. Prevalence of Clostridium difficile Toxins $\mathrm{A}$ and $\mathrm{B}$ and Clostridium perfringens Enterotoxin A in Stool Samples of Patients with Antibiotic-Associated Diarrhea. Infection2005; 33:340-4.

21. Jamal W, Rotimi VO, Brazier J, Duerden BI. Analysis of prevalence, risk factors and molecular epidemiology of Clostridium difficile infection in Kuwait over a 3-year period. Anaerobe 2010; 16: $560-5$.

22. George WL, Sutter VL, Citron D, Finegold SM. Selective and differential medium for isolation of Clostridium difficile. J ClinMicrobiol1979; 9: 214-9.

23. Dilip Pawar, Prasan Bhandari, Kent Allenby. Clostridium Difficile-Associated Diarrhea: A Review. Indian Medical Gazette — DEC 2011.
24. John D. Perry, Kerry Asir, Diane Halimi, Sylvain Orenga, Joanne Dale, Michelle Payne, Ruth Carlton,Jim Evans, Evaluation of a chromogenic culture medium for isolation of Clostridium difficile in 24 hours hours. $\mathrm{J}$ Clin Microbiol. 2010 November; 48(11): 3852-3858.

25. Cohen SH, Gerding DN, Johnson S, Kelly CP, Loo VG, McDonald LCetal. Clinical Practice Guidelines for Clostridium difficile Infection in Adults: 2010 Update by the Society for Healthcare Epidemiology of America (SHEA) and the Infectious Diseases Society of America (IDSA). Infect Control Hosp Epidemiol 2010; 31: 431-55.

26. Thompson CM Jr, Gilligan PH, Fisher MC, Long SS. Clostridium difficile cytotoxin in a paediatric population. Am J Dis Child 1983; 137 : 271-4.

27. Bhattacharya MK, Niyogi SK, Rasaily R, Bhattacharya SK, Dutta P, Nag A, et al. Clinical manifestation of Clostridium difficile enteritis in Calcutta. J Assoc PhysiciansIndia 1991; 39: 683-4.

28. Vaishnavi C, Kochhar R, Bhasin DK, Thapa BR, Singh K. Detection of Clostridium difficile toxin by an indigenously developed latex agglutination assay. Trop Gastroenterol1999; 20:33-5

29. Wong NA, Bathgate AJ, Bellamy CO. Colorectal disease in liver allograft recipients: A clinicopathological study with follow up. Eur J Gastroenterol Hepatol 2002; 14:231-6.

30. Vaishnavi C, Bhasin DK, Kochhar R, Singh K Clostridium difficile toxin and faecal lactoferrin assays in adult patients. Microbes Infect 2000;2:1827-30

31.West M, Pirenne J, Chavers B, Gillingham K, Sutherland DE, Dunn DL, et al. Clostridium diffcile colitis after kidney and kidney-pancreas transplantation. Clin Transplant 199913 :318-23.

32. Dallal RM, Harbrecht BG, Boujoukas AJ, Sirio CA, Farkas LM, Lee KK, et al. Fulminant Clostridium difficile:An underappreciated and increasing cause of death andcomplications. Ann Surg 2002;235:363-72.

33. Wong NA, Bathgate AJ, Bellamy CO. Colorectal disease inliver allograft recipients: A clinicopathological study withfollow up. Eur J Gastroenterol Hepatol 2002; 14:231-6. 


\section{Original Research Article}

34. Emoto M, Kawarabayashi T, Hachisuga T, Eguchi F,Shirakawa K. Clostridium difficile colitis associated with cisplatin-based chemotherapy in ovarian cancer patients.GynecolOncol 1996;61:369-72

35. Kumar B, Vaishnavi C, Sandhu K, Kaur I. Clostridium difficile toxin assay in psoriatic patients. Trop Gastroenterol2004; 25:164-7.

36. Bliss DZ, Johnson S, Savik K, Clabot CR, Willard $\mathrm{K}$, Gerding DN. Acquisition of Clostridium difficile and Clostridium difficile-associated diarrhea in hospitalised patients receiving tube feeding. Ann Intern Med 1998;129: 1012-9.
37. Lowe DO, Mamdani MM, Kopp A, Low DE, Juurlink DN.Proton pump inhibitors and hospitalization for Clostridium difficile .associated disease: A population- based study. ClinInfect Dis 2006;43:1272-6

38. Balamurugan R, Balaji V, Ramakrishna BS. Estimation of faecal carriage of Clostridium difficile in patients with ulcerative colitis using real time polymerase chain reaction. Indian J Med Res. 2008; 127 : 472-7

39. Feketly R, Shah AB. Diagnosis and treatment of Clostridium difficile colitis. JAMA 1993; 269: 71-5.

\section{How to cite this article?}

Lall S, Nataraj G, Mehta P. Estimation of prevalence and risk factors for clostridium difficile infection: a neglected pathogen in a tertiary care setting in India. Int J Med Res Rev 2017;5(03):298-309 doi:10.17511/ijmrr. 2017.i03.14. 